\title{
Hypogonadism and liver fibrosis in HIV-infected patients
}

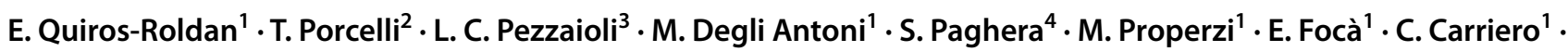 \\ F. Castelli ${ }^{1} \cdot$ A. Ferlin ${ }^{3}$ (1)
}

Received: 18 November 2020 / Accepted: 16 January 2021 / Published online: 29 January 2021

(c) The Author(s) 2021

\begin{abstract}
Purpose Hypogonadism is frequent in HIV-infected men and might impact on metabolic and sexual health. Low testosterone results from either primary testicular damage, secondary hypothalamic-pituitary dysfunction, or from liver-derived sex-hormone-binding-globulin (SHBG) elevation, with consequent reduction of free testosterone. The relationship between liver fibrosis and hypogonadism in HIV-infected men is unknown. Aim of our study was to determine the prevalence and type of hypogonadism in a cohort of HIV-infected men and its relationship with liver fibrosis.

Methods We performed a cross-sectional retrospective study including 107 HIV-infected men (median age 54 years) with hypogonadal symptoms. Based on total testosterone (TT), calculated free testosterone, and luteinizing hormone, five categories were identified: eugonadism, primary, secondary, normogonadotropic and compensated hypogonadism. Estimates of liver fibrosis were performed by aspartate aminotransferase (AST)-to-platelet ratio index (APRI) and Fibrosis-4 (FIB-4) scores. Results Hypogonadism was found in 32/107 patients (30.8\%), with normogonadotropic (10/107, 9.3\%) and compensated $(17 / 107,15.8 \%)$ being the most frequent forms. Patients with secondary/normogonadotropic hypogonadism had higher body mass index (BMI) $(p<0001)$. Patients with compensated hypogonadism had longer HIV infection duration $(p=0.031)$, higher APRI $(p=0.035)$ and FIB-4 scores $(p=0.008)$, and higher HCV co-infection. Univariate analysis showed a direct significant correlation between APRI and TT $(p=0.006)$ and SHBG $(p=0.002)$, and between FIB-4 and SHBG $(p=0.045)$. Multivariate analysis showed that SHBG was independently associated with both liver fibrosis scores.

Conclusion Overt and compensated hypogonadism are frequently observed among HIV-infected men. Whereas obesity is related to secondary hypogonadism, high SHBG levels, related to liver fibrosis degree and HCV co-infection, are responsible for compensated forms.
\end{abstract}

Keywords Hypogonadism $\cdot$ HIV $\cdot$ Liver fibrosis $\cdot$ Testosterone $\cdot$ LH $\cdot$ SHBG

A. Ferlin

alberto.ferlin@unibs.it

1 Department of Infectious and Tropical Diseases, University of Brescia and ASST Spedali Civili Hospital, Brescia, Italy

2 Endocrinology, Montichiari Hospital, ASST Spedali Civili Brescia, Montichiari, Brescia, Italy

3 Unit of Endocrinology and Metabolism, Department of Clinical and Experimental Sciences, University of Brescia and ASST Spedali Civili Brescia, Viale Europa 11, 25123 Brescia, Italy

4 Diagnostic Department, ASST Centro di Ricerca Emato-oncologica AIL (CREA), Spedali Civili di Brescia, Brescia, Italy

\section{Introduction}

Hypogonadism is a clinical syndrome characterized by low testosterone (T) plasma levels with symptoms and signs of low androgen action, caused by alteration of the hypothalamus-pituitary-testis axis (HPT) at one or more stages [1, 2]. Sexual symptoms, such as decreased libido and erectile dysfunction, are considered the most specific manifestations, but many other conditions and co-morbidities are associated with hypogonadism, for example osteoporosis, increased fat/lean mass, cardiovascular diseases, sarcopenia, asthenia, and depression [3]. Hypogonadism is a relatively common finding in men with HIV, although its prevalence is at present lower comparing to the preantiretroviral therapy (ART) era [4, 5]. Current estimates on the prevalence of hypogonadism in HIV-infected men 
generally range from 13 to $40 \%$ according to different study settings, mainly depending on the criteria and T-levels cut-offs used for its diagnosis [6, 7]. Importantly, hypogonadism in HIV-infected men might result from either testicular disorder (primary hypogonadism) or hypothalamic-pituitary dysfunction (secondary hypogonadism); however, only few studies differentiated between these two forms by testing luteinizing hormone (LH) levels, which are elevated in the former case and low/normal in the latter. Furthermore, compensated hypogonadism, which represents another frequent finding in both, general population and HIV-infected men complaining of sexual dysfunction, can be diagnosed by LH determination, since it is characterized by normal T levels and high LH [8-10]. Hypogonadism can also be linked to sex-hormone binding protein (SHBG) alteration. In fact, androgen actions are mediated by free $\mathrm{T}(\mathrm{FT})$, which represents only $1-3 \%$ of total $\mathrm{T}$, being the large part bound to albumin and SHBG, both produced by the liver. Therefore, in conditions in which SHBG is high (as liver diseases or HIV infection), determination of FT is necessary because total T (TT) might be apparently normal [11]. Moreover, methods that directly measure FT are inaccurate; the best approach is represented by its calculation (calculated FT, cFT) after determination of SHBG and albumin using formulae, as the Vermeulen one (http://www.issam.ch/freetesto.htmww w.issam.ch/freetesto.htm).

However, liver function, SHBG, LH and FT levels have been rarely evaluated together in HIV-infected men. Interestingly, the liver and the reproductive system are bidirectionally linked. Sex steroid signaling influences hepatic metabolism and contributes to the pathogenesis of functional and structural disorders of the liver [12]. In turn, liver function affects the reproductive axis modulating not only SHBG levels, but also sex steroid metabolism [13]. In the general population $\mathrm{T}$ is reduced in up to $90 \%$ of men with cirrhosis [12] and in male patients with HCV-related chronic liver diseases [14]. In addition, the relationship between sex hormones and SHBG levels and Non Alcoholic Steato Hepatitis (NASH), Non Alcoholic Fatty Liver Disease (NAFLD) and liver fibrosis has been reported in some studies [15-21], although with non-conclusive data.

In people living with HIV many overlapping factors contribute to the development of liver injury and progressive hepatic fibrosis, as HCV, HBV or HDV co-infections, alcohol or drugs abuse, chronic ART and fatty liver disease. Therefore, an accurate study regarding hypogonadism and liver fibrosis in men with HIV-infection is warranted.

The aim of this study was the determination of the prevalence and type of hypogonadism based on cFT, TT, SHBG and LH values in a cohort of middle-aged HIV-infected males with symptomatic hypogonadism and its relationship with liver fibrosis measured by Fibrosis-4 (FIB-4) and aspartate aminotransferase (AST)-to-platelet ratio index (APRI) scores.

\section{Methods}

\section{Setting and study population}

A cross-sectional observational retrospective study was performed. One-hundred and seven HIV-infected male patients under ART followed at our Clinic with hypogonadal symptoms (erectile dysfunction, reduced libido and morning spontaneous erections) were selected from a database of patients who underwent endocrinological evaluation from January 2012 to December 2019. Inclusion criteria were: age $>18$ years, HIV infection under ART in stable clinical condition, sexual symptoms and availability of complete data for TT, cFT (calculated with the Vermeulen formula), SHBG, LH, AST, alanine aminotransferase (ALT), gammaglutamyl transferase (GGT), platelets (PLT), and HCV data ( $\mathrm{Ab}$ and RNA) from the same reference laboratory. TT and LH were determined using chemiluminescence microparticle immunoassay (CMIA), SHBG using chemiluminescence immunoassay (CLIA). Exclusion criteria were previous or current use of drugs affecting HPT axis, acute illnesses, known pituitary and testicular diseases, cancer, diabetes mellitus, chronic renal failure, laboratory data not coming from the reference laboratory of our Hospital. Demographic and clinical characteristic were recorded from clinical charts.

According to guidelines [22], patients were grouped by their HPT status in five categories: (a) eugonadism, defined as normal TT $(>3.46 \mathrm{ng} / \mathrm{ml})$, cFT $(>65 \mathrm{pg} / \mathrm{ml})$, and $\mathrm{LH}$ ( $>1.5<9.4 \mathrm{IU} / \mathrm{l})$; (b) compensated hypogonadism, defined as normal TT $(>3.46 \mathrm{ng} / \mathrm{ml})$ and cFT $(>65 \mathrm{pg} / \mathrm{ml})$ and elevated LH (>9.4 IU/l); (c) secondary hypogonadism, defined as low TT $(\leq 3.46 \mathrm{ng} / \mathrm{ml})$ or cFT $(\leq 65 \mathrm{pg} / \mathrm{ml})$ and low LH ( $\leq 1.5 \mathrm{IU} / \mathrm{l})$; (d) primary hypogonadism, defined as low TT $(\leq 3.46 \mathrm{ng} / \mathrm{ml})$ or cFT $(\leq 65 \mathrm{pg} / \mathrm{ml})$ and elevated LH (>9.4 IU/l); (e) normogonadotropic hypogonadism, defined as low TT $(\leq 3.46 \mathrm{ng} / \mathrm{ml})$ or $\mathrm{cFT}(\leq 65 \mathrm{pg} / \mathrm{ml})$ and normal $\mathrm{LH}(>1.5<9.4 \mathrm{IU} / \mathrm{l})$.

Estimates of liver fibrosis were performed by the APRI score [23], calculated as [AST (U/l)/upper normal $\times 100 /$ platelet count $\left.\left(10^{9} / 1\right)\right]$, available at https://www.hepat itisc.uw.edu/page/clinical-calculators/apri, and the FIB-4 score [24], calculated as [Age (years) $\times$ AST $($ U/l)/[PLT $\left.\left(10^{9} / \mathrm{l}\right) \times \mathrm{ALT} 1 / 2(\mathrm{U} / \mathrm{l})\right]$, available at https://www.hepatitisc .uw.edu/page/clinical-calculators/fib-4.

\section{Statistical analysis}

GraphPad Prism version 5.1 (GraphPad Software, San Diego, CA) was used for statistical analysis. Comparison 
among medians of the quantitative variables were performed by non-parametric Kruskal-Wallis $H$ test, since the variables were not normally distributed (D'Agostino and Pearson omnibus normality test was used). When the interaction was significant, post hoc Dunn's test corrected $p$ values were calculated. The Spearman's correlation was calculated to verify the possible association with TT and cFT of the variables used. The association between liver fibrosis scores (FIB-4 and APRI) and age, BMI, HIV duration, HCV ab, and hormonal data was analysed with univariate and multivariate regression models. $p$ values $\leq 0.05$ were considered significant.

\section{Ethics}

This study was conducted according to the Declaration of Helsinki and to principles of Good Clinical Practice (GCP). As this study had a retrospective design and was based on routinely collected data, patients' informed consent was not required according to the Italian law (Italian Guidelines for classification and conduction of observational studies, established by the Italian Drug Agency, "Agenzia Italiana del Farmaco-AIFA" on March 20, 2008). Moreover, the study protocol was approved by the local Ethic Committee of Brescia Province (Comitato Etico di Brescia-August 2020 NP 3898). Data were analyzed anonymously, and each subject was identified using an alphanumerical code.

All authors had access to the study data and reviewed and approved the final manuscript.

\section{Results}

\section{Patients' characteristics}

One hundred and seven patients were included in the study. Table 1 summarize their characteristics. The median age was 54 years (IQR 48-58) and median body mass index (BMI) 25 (IQR 23-27). 40\% were smokers and $41 \%$ were $\mathrm{HCV} \mathrm{Ab}$ positive (of which $61 \%$ with a detectable plasmatic HCVRNA). With respect to liver function, the proportion of patients with AST, ALT and GGT above upper normal limits was 14/107 patients (13.1\%), 31/107 (28.9\%) and 27/107 (25.2\%), respectively. Median APRI and FIB-4 score were 0.3 (IQR 0.2-0.4) and 1.1 (IQR (0.8-1.5), respectively. The proportion of patients with severe fibrosis defined as APRI score $>1$ or FIB-4 score $>2.67$ were $16.6 \%(18 / 107)$ and $14 \%$ (15/107), respectively.

\section{Hypogonadism and liver fibrosis}

The prevalence of overt hypogonadism (defined as patients with low level of TT and/or cFT and including primary, secondary and normogonadotropic hypogonadism) was $14 \%$ (15/107). Normogonadotropic hypogonadism was the most frequent type (10/107, 9.3\%). An additional 15.8\% (17/107) had compensated hypogonadism (Table 1). Analyses were performed grouping together secondary and normogonadotropic hypogonadism (Table 1).

Patients with secondary/normogonadotropic hypogonadism were significantly more obese $(\mathrm{BMI}>30)$ with respect to patients with eugonadism and primary and compensated hypogonadism $(p<0001)$. Patients with compensated hypogonadism had longer duration of HIV positivity $(p=0.031)$ and higher APRI $(p=0.035)$ and FIB-4 indexes $(p=0.008)$ compared to patients with eugonadism and primary and secondary/normogonadotropic hypogonadism (Table 1). Moreover, although not statistically different to the other groups, they tended to have more frequently a detectable HCVRNA and showed higher SHBG and transaminases. The low number of patients with primary hypogonadism $(n=3)$ did not allow to perform analyses on this group.

Table 2 shows reproductive hormonal levels according to liver fibrosis scores upper or under the mean. SHBG values were higher in patients with APRI score upper the mean ( $102 \mathrm{nmol} / \mathrm{l}$ vs $54 \mathrm{nmol} / \mathrm{l}$ in patients with APRI score below the mean; $p=0.004$ ) and a trend for difference also observed when compared according to FIB-4 score $(66 \mathrm{nmol} / \mathrm{l}$ vs $56 \mathrm{nmol} / \mathrm{l} ; p=0.072$ ). LH values were higher in patients with FIB-4 upper the mean (7.0 IU/l vs $5.1 \mathrm{IU} / 1 ; p=0.017)$ and a trend also observed when considering APRI score (7.1 IU/1 vs $5.1 \mathrm{IU} / 1 ; p=0.060$ ).

\section{Correlation between TT, CFT, SHBG, LH and liver fibrosis}

Finally, we analyzed the relationship between HPT markers and liver fibrosis. As showed in Fig. 1, a direct significant correlation was found between APRI score and TT $(r=0.223 ; p=0.006)$ and SHBG $(r=0.331 ; p=0.002)$; no correlation was found with cFT and LH levels. FIB-4 score positively correlated with SHBG $(r=0.211 ; p=0.045)$. Multivariate analysis showed that only SHBG was independently associated with both liver fibrosis scores (APRI $p<0.0001$; FIB-4 $p=0.002$ ).

\section{Discussion}

Overall, in this cohort of HIV-infected patients the prevalence of hypogonadism was $30 \%$. The most prevalent categories were compensated hypogonadism $(15.8 \%)$ and hypogonadism with normal/low LH levels (11.2\%). These two groups of patients showed characteristics suggesting a different pathophysiological mechanism. Compensated 
Table 1 Characteristics of the study population

\begin{tabular}{|c|c|c|c|c|c|c|c|}
\hline & Normal range & $\begin{array}{l}\text { Overall } \\
(\#=107)\end{array}$ & $\begin{array}{l}\text { Secondary-nor- } \\
\text { mogonadotropic } \\
\text { hypogonadism } \\
(\#=12)\end{array}$ & $\begin{array}{l}\text { Compensated hypo- } \\
\text { gonadism } \\
(\#=17)\end{array}$ & $\begin{array}{l}\text { Primary hypog- } \\
\text { onadism } \\
(\#=3)\end{array}$ & $\begin{array}{l}\text { Eugonadism } \\
(\#=75)\end{array}$ & $p$ value \\
\hline $\begin{array}{l}\text { Age (years); median } \\
\text { (IQR) }\end{array}$ & & $54(48-58)$ & $51(46-57)$ & $55(49-58)$ & $61(54-64)$ & $54(48-58)$ & 0.3291 \\
\hline BMI [median (IQR)] & & $25(23-27)$ & $26(25-31)$ & $24(23-27)$ & $25(24-30)$ & $25(23-27)$ & 0.2999 \\
\hline$>30 ; \#(\%)$ & & $14(13)$ & $8(67)$ & $1(6)$ & $1(33)$ & $4(5)$ & $<0.0001$ \\
\hline Smoker; \# (\%) & & $43(40)$ & $3(25)$ & $9(53)$ & $1(33)$ & $30(40)$ & 0.5008 \\
\hline Diabetic; \# (\%) & & $14(13)$ & $2(17)$ & $4(24)$ & $1(33)$ & $7(9)$ & 0.2867 \\
\hline $\begin{array}{l}\text { HCV Ab positive; } \\
\quad \#(\%)\end{array}$ & & $44(41)$ & $5(42)$ & $11(65)$ & $3(100)$ & $25(33)$ & 0.0179 \\
\hline $\begin{array}{l}\text { HCV RNA positive }{ }^{\mathrm{a}} ; \\
\quad \#(\%)\end{array}$ & & $27(61)$ & $2(17)$ & $10(91)$ & $1(33)$ & $14(56)$ & 0.0975 \\
\hline AST; median (IQR) & $18-39$ & $21(16-30)$ & $20.5(14-27)$ & $29.0(20-45)$ & $16.0(16-31)$ & $21.0(16-29)$ & 0.2215 \\
\hline ALT; median (IQR) & $15-47$ & $34(26-50)$ & $38(31.5-54)$ & $48(30.5-63.5)$ & $26(18-51)$ & $32(25-45)$ & 0.1063 \\
\hline GGT; median (IQR) & $10-71$ & $44(27-86)$ & $57(21.8-142)$ & $48(31-89)$ & $39(26-48)$ & $44(25.5-84)$ & 0.7317 \\
\hline PLT; median (IQR) & $130-400$ & $190(161-233)$ & $230(186.5-275.5)$ & $200(142-246.5)$ & $162(145-175)$ & $188(156-230)$ & 0.1140 \\
\hline TT; median (IQR) & $3-9$ & $6.5(5.2-8.5)$ & $4.4(2.8-4.6)$ & $7(6-8.6)$ & $3.3(2.5-4.2)$ & $6.7(5.4-8.6)$ & 0.0001 \\
\hline cFT; median (IQR) & $65-260$ & $101(70.2-122.3)$ & $54.8(21.8-61.7)$ & $108(68.4-146)$ & $41.4(32.6-55)$ & $108.5(87.6-128)$ & $<0.0001$ \\
\hline $\begin{array}{l}\text { SHBG; median } \\
\text { (IQR) }\end{array}$ & $10-70$ & $60(41-87)$ & $56(36.5-99)$ & $90(52.9-107.5)$ & $43(41.6-117)$ & $59.5(38.8-69.8)$ & 0.5906 \\
\hline LH; median (IQR) & $1.5-9.0$ & $5.6(3.5-8.6)$ & $3.9(2.3-7.5)$ & $15.7(10.7-26.8)$ & $23.6(11.2-30.5)$ & $4.6(3-6.9)$ & $<0.0001$ \\
\hline FSH; median (IQR) & $1.5-8.0$ & $5.9(4.2-9.5)$ & $5.2(3.1-.15 .7)$ & $10(6.2-16.4)$ & $33.8(15.9-51.8)$ & $5.5(4-7.9)$ & 0.0021 \\
\hline \multicolumn{8}{|l|}{ APRI } \\
\hline Mean (SD) & & $0.5(0.9)$ & $0.75(1.7)$ & $1.0(1.5)$ & $0.3(0.2)$ & $0.4(0.3)$ & 0.0352 \\
\hline Median (IQR) & & $0.3(0.2-0.4)$ & $0.2(0.13-0.38)$ & $0.40(0.2-1.1)$ & $0.20(0.2-0.5)$ & $0.3(0.2-0.4)$ & 0.3412 \\
\hline \multicolumn{8}{|l|}{ FIB-4 } \\
\hline Mean (SD) & & $1.5(1.6)$ & $1.5(2.4)$ & $2.6(2.9)$ & $1.4(0.2)$ & $1.2(0.7)$ & 0.0084 \\
\hline Median (IQR) & & $1.1(0.8-1.5)$ & $0.73(0.53-1.3)$ & $1.0(0.69-5.17)$ & $1.42(1.15-1.62)$ & $1.05(0.81-1.37)$ & 0.1518 \\
\hline $\begin{array}{l}\text { Years with HIV; } \\
\text { median (IQR) }\end{array}$ & & $18(12-25)$ & $15(13-17)$ & $30(19-33)$ & $22(11-24)$ & $17(11-24)$ & 0.0137 \\
\hline $\begin{array}{l}\text { Years of ART; } \\
\text { median (IQR) }\end{array}$ & & $15(10-23)$ & $14(10-17)$ & $23(13-24)$ & $22(11-22)$ & $13(8-23)$ & 0.0830 \\
\hline $\begin{array}{l}\text { CD } 4 / \mu 1 ; \text { median } \\
\text { (IQR) }\end{array}$ & & $636(456-793)$ & $559(506-682)$ & $636(537-799)$ & $376(256-1272)$ & $660(350-829)$ & 0.7708 \\
\hline $\begin{array}{l}\text { CD4\%; median } \\
\text { (IQR) }\end{array}$ & & $30.5(23.9-37.6)$ & $32.1(26.8-42.6)$ & $30.4(26.5-38.3)$ & $16.5(14.7-36.6)$ & $31.3(23.5-35.6)$ & 0.3402 \\
\hline $\begin{array}{l}\mathrm{CD} 4 \text { nadir/ } / \mathrm{l} ; \\
\text { median (IQR) }\end{array}$ & & $125(49-281)$ & $184(24-344)$ & $125(46-261)$ & $63(21-290)$ & $126(54-294)$ & 0.8885 \\
\hline $\begin{array}{l}\text { CD8/ } \mu \mathrm{l} ; \text { median } \\
\text { (IQR) }\end{array}$ & & 774 (524-1099) & $697(432-922)$ & 798 (599-1062) & $1294(941-1533)$ & 774 (521-1116) & 0.1584 \\
\hline $\begin{array}{l}\text { CD8\%; median } \\
\text { (IQR) }\end{array}$ & & $39.6(31.9-46.7)$ & $36.9(33.9-44.7)$ & $40.2(23.7-46.5)$ & $59.7(37.2-60.9)$ & $39.6(31.3-49.5)$ & 0.2845 \\
\hline $\begin{array}{r}\text { CD4/CD8 ratio; } \\
\text { median (IQR) }\end{array}$ & & $0.80(0.52-1.14)$ & $0.82(0.63-1.21)$ & $0.8(0.6-0.95)$ & $0.27(0.25-0.98)$ & $0.79(0.5-1.26)$ & 0.4330 \\
\hline AIDS; \# (\%) & & $31(29)$ & $4(33)$ & $5(29)$ & $2(66)$ & $20(27)$ & 0.4978 \\
\hline
\end{tabular}

$B M I$ body mass index $\left(\mathrm{kg} / \mathrm{m}^{2}\right), N A$ not available, $A S T$ aspartate transaminase (U/l), $A L T$ alanine transaminase (U/l), GGT gamma-glutamyl transferase $(\mathrm{U} / \mathrm{l}), P L T$ thrombocyte $\left(\times 10^{3} / \mu \mathrm{l}\right), T T$ total testosterone $(\mathrm{ng} / \mathrm{ml}), c F T$ free testosterone $(\mathrm{pg} / \mathrm{ml}), S H B G$ sex hormone binding globulin (nmol/l), LH luteinizing hormone (IU/l), FSH follicle-stimulating hormone (IU/l), APRI the aspartate aminotransferase (AST)-to-platelet ratio index, FIB-4 fibrosis-4 index, $A R T$ antiretroviral therapy

$p$ value was done by Kruskal-Wallis $H$ test for continuous variables and Chi-square test for categorical variables. For APRI and FIB-4 mean values, $p$ value was done by one-way analysis of variance and Bonferroni's multiple comparison test

${ }^{a} \mathrm{HCV}$ RNA positive patients are calculated from the number of HCV Ab positive patients 
Table 2 Reproductive hormones levels according to liver fibrosis scores in the cohort analyzed

\begin{tabular}{|c|c|c|c|c|c|c|}
\hline & \multicolumn{3}{|l|}{ APRI } & \multicolumn{3}{|l|}{ FIB-4 } \\
\hline & $<0.47(\#=86)$ & $\geq 0.47(\#=21)$ & $p$ value $^{\mathrm{a}}$ & $<1.40(\#=78)$ & $\geq 1.40(\#=29)$ & $p$ value $^{\mathrm{a}}$ \\
\hline TT; median (IQR) & $6.4(5-8.2)$ & $7.0(5.5-9.4)$ & 0.151 & $6.4(4.9-8.6)$ & $6.9(5.3-8.3)$ & 0.569 \\
\hline FT; median (IQR) & $103(69.6-126)$ & $94.2(68-117.8)$ & 0.688 & $103(71.7-129)$ & $94.2(66-116.3)$ & 0.555 \\
\hline SHBG; median (IQR) & $54(38.7-69)$ & $102(53.1-118)$ & 0.004 & $56(38.5-70.5)$ & $66(44.1-106)$ & 0.072 \\
\hline LH; median (IQR) & $5.1(3.8-8.1)$ & $7.1(3.9-11.9)$ & 0.060 & $5.1(3-7.9)$ & $7(4-13.2)$ & 0.017 \\
\hline
\end{tabular}

APRI and FIB-4 columns were divided according to the mean of APRI and FIB-4 in overall patients

$T T$ total testosterone (ng/ml), FT free testosterone (pg/ml), SHBG sex hormone binding globulin (nmol/l), LH luteinizing hormone (U/l)

${ }^{\mathrm{a}} p$ value calculation was done by Fisher exact test for categorial variables and Mann-Whitney test for continuous variables

Fig. 1 Correlation between TT, cFT, SHGB, LH and liver fibrosis
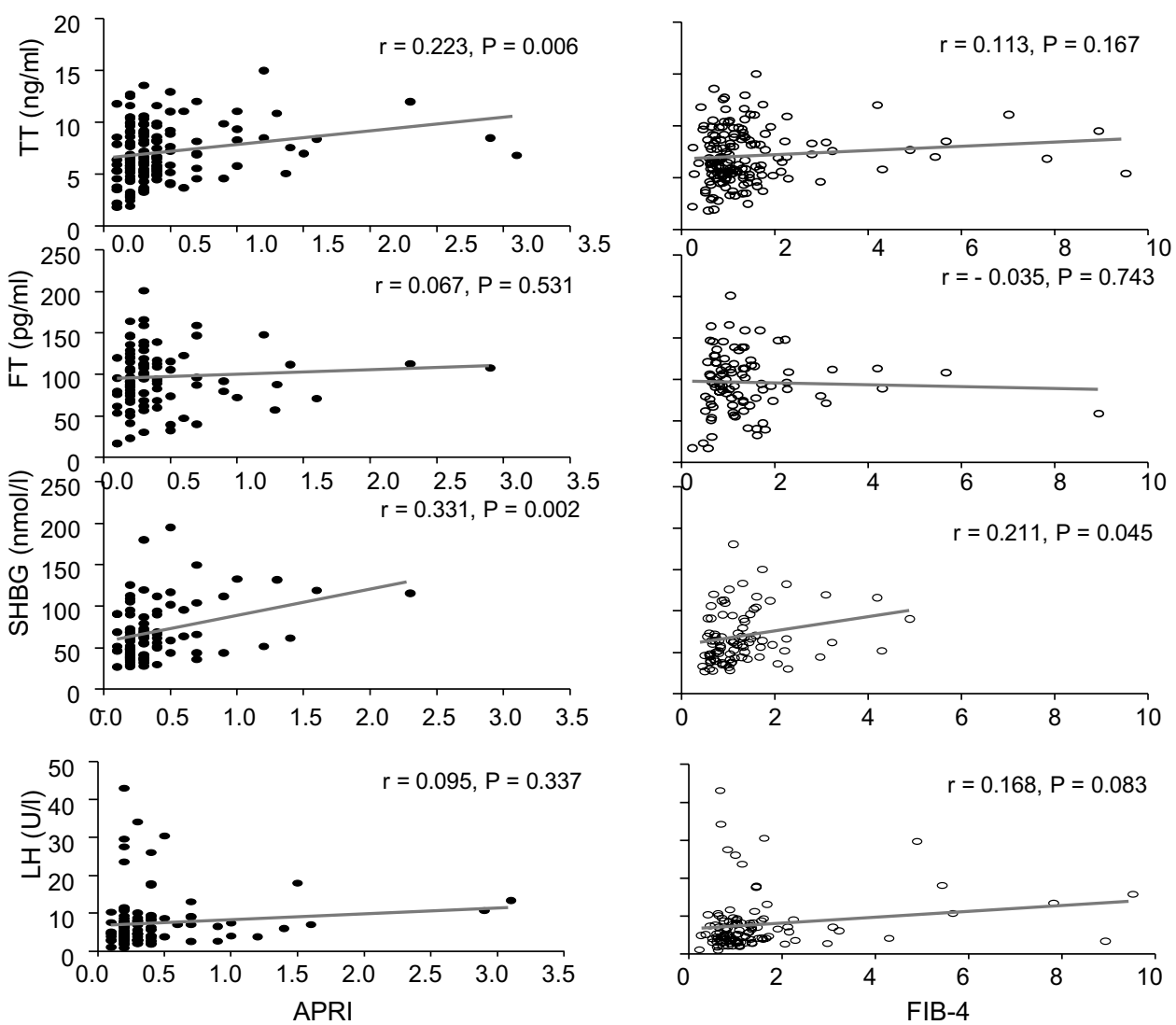

hypogonadism was associated with higher SHBG levels and liver fibrosis scores, together with longer duration of HIV infection. Furthermore, this group had also higher prevalence of detectable plasmatic HCVRNA. Importantly, liver fibrosis positively correlated with SHBG and TT levels as previously described [15-21]. As summarized in Fig. 2, our data suggest that in compensated forms T levels are maintained within normal range by an increase of $\mathrm{LH}$ production secondary to higher SHBG levels induced by liver fibrosis. SHBG level was associated to liver fibrosis independently of age, BMI, HCV ab or HIV duration. The maintenance of normal $\mathrm{T}$ concentrations relates to a normal HPT axis function, as pituitary gland should be able to respond to lower $\mathrm{T}$ levels induced by increased SHBG, and the testis should be able to increase steroidogenesis in response to LH. Therefore, the primum movens for hypogonadism onset in these patients seems to be liver dysfunction, as they show a normal function of HPT axis. The overall clinical and physiological significance of compensated hypogonadism is poorly understood. In a population-based study of European men aged 40-79, compensated hypogonadism was associated with a highest frailty score [10]. In a big Italian study including 4173 patients consulting for sexual dysfunction, individuals with compensated hypogonadism reported psychiatric symptoms more often and had an increased predicted risk 


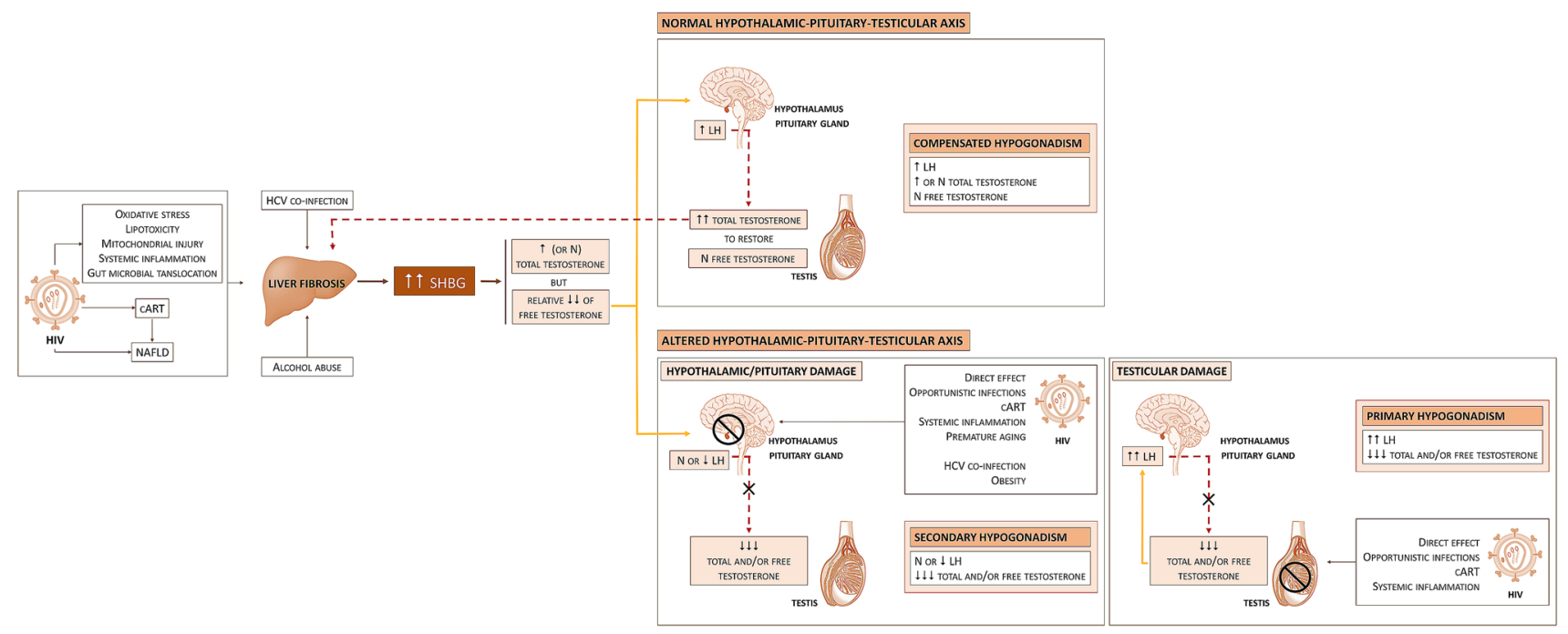

Fig. 2 Potential impact of liver damage on the pathogenesis of hypogonadism in HIV-infected men. HIV human immunodeficiency virus, $c A R T$ combined anti-retroviral therapy, $N A F L D$ nonalcoholic fatty

of cardiovascular events when compared with eugonadal individuals in general population [25].

On the contrary, in the second group of patients, with overt hypogonadism (low $\mathrm{T}$ levels) and normal/low $\mathrm{LH}$ values, LH is not increased and, therefore, the Leydig cell steroidogenic activity is not stimulated to maintain normal $\mathrm{T}$ production. In these patients, a certain grade of hypothalamic-pituitary dysfunction is plausible, so that there is an inadequate response to liver dysfunction and increased SHBG levels. Interestingly, patients in this group were more frequently obese, and it is well known that obesity is among the most frequent cause of secondary/normogonadotropic hypogonadism [26]. Focusing on the known body fat redistribution due to HIV-induced lipodystrophy, the relationship between body fat (not necessarily obesity) and gonadal status was recently evaluated by De Vincentis and colleagues [27]. They found that $\mathrm{cFT}$ and TT were inversely related, whereas oestradiol was directly related to total body and visceral fat, and therefore hypothesized that these findings could depend on an increase of testosterone aromatization, similarly to what happens in obese hypogonadal men of general population. Normogonadotropic hypogonadism is also called functional hypogonadism [22], indicating that low T levels occur in the absence of both intrinsic structural HPT axis pathology and of specific pathological conditions suppressing the HPT axis (e.g., prolactinoma). Indeed, HIV per se, obesity and increased SHBG are indicated as possible causes of functional hypogonadism [22, 28].

Systemic low chronic inflammation together with liver dysfunction, two frequent conditions in HIV population, might also be implied in the relative suppression of hypothalamus-pituitary function in this group of patients (Fig. 2). liver disease, $H C V$ hepatitis $\mathrm{C}$ virus, $S H B G$ sex hormone binding globulin, $L H$ luteinizing hormone

Finally, primary hypogonadism was uncommon $(2.8 \%)$ in our cohort of middle-aged HIV-infected patients, in agreement with previous reports [28]. Although the low number of patients affected by primary hypogonadism did not allow us detailed analyses, this form seems not to be related with liver fibrosis. In these cases, the primary testicular damage may be associated with a direct effect of HIV, opportunistic infections, long-term ART exposure and systemic inflammation on the testis [28] (Fig. 2).

Although many studies have been performed about hypogonadism in men with HIV, the cause and pathophysiological mechanisms of hypogonadism have not been clarified yet. Besides the usual risk factors for hypogonadism as the general population, HIV-related risk factors for hypogonadism include the duration of HIV infection, duration of ART, number of comorbidities, concomitant liver disease with $\mathrm{HBV}$ or $\mathrm{HCV}$ or non-alcoholic fatty liver disease, and presence of inflammatory cytokines such as tumor necrosis factor- $\alpha$ (TNF- $\alpha)$ or interleukin-1 [29-31].

Our study is the first to examine the possible involvement of liver dysfunction/fibrosis in hypogonadism among middle-aged HIV-infected patients, having also the advantage of considering LH levels as marker of hypothalamus-pituitary function and cFT as a more sensitive marker of hypogonadism than TT. Most of the studies on hypogonadism in patients with HIV-infection focused only on TT levels, very few included also gonadotropins, and none included liver fibrosis data [28].

The association between liver dysfunction and T metabolism is extensively described in the general population, but yet not fully understood [12, 14-21, 32]. Many factors may contribute to hypogonadism in cirrhosis, including 
hepatic overproduction of SHBG, changed SHBG isoforms with different steroid-binding affinities, elevated prolactin levels, direct suppression of Leydig cell function by estrogens or increased estrogen receptors in the liver [32]. A recent study [20] found that low cFT was associated with presence of NASH and severity of fibrosis in patients with histologically confirmed NAFLD. In agreement with this study, which was remarkably performed on liver biopsies, but also with another one based on non-invasive FIB-4 score [21], we showed that hypogonadism is frequent among middle-aged HIV-infected patients and it seems to be especially present in patients with high SHBG levels, liver fibrosis and HCV co-infection. These studies [20, 21], however, did not evaluate the HPT axis, therefore are not conclusive about the correlation between presence and/ or grade of liver fibrosis and several classes of hypogonadism, especially because they did not study compensated hypogonadism forms.

Another strength of our study is the inclusion of only symptomatic patients. The diagnosis of hypogonadism should be based on the association between low $\mathrm{T}$ levels and clinical symptoms/signs of T deficiency, of which sexual symptoms are considered the most specific [22]. Indeed, most studies on HIV population did not consider hypogonadal symptoms, but rather assessed biochemical hypogonadism. In turn, this is important because the treatment of hypogonadism (usually with $\mathrm{T}$ replacement therapy, unless the patient is interested in fertility) is recommended only in symptomatic men with low T levels [22].

Interestingly, despite including only hypogonadal symptomatic patients, two thirds of them did not have a biochemical confirmation of any form of hypogonadism, suggesting that, at least in part, sexual symptoms can also be associated with other clinical and psychological HIV-infection-related aspects [33, 34].

We acknowledge some limitations in our study, including the small single-center cohort, the absence of determination of estradiol and albumin values, the lack of data on body composition and fat body distribution besides BMI and the absence of a control group without HIV-infection. Furthermore, this is a retrospective study and liver fibrosis assessment was performed with indirect scoring systems, such as the APRI and FIB-4 scores, instead of abdominal ultrasonography/elastography or liver biopsy, which is the gold standard both in general and HIV-infected populations [35]. However, also these methods have limitations: ultrasonography has limited accuracy in detecting fatty liver when $<35 \%$ of hepatocytes have been affected [36], and performing liver biopsy for patients who do not meet indications raises ethical considerations. Given the limitations of instrumental and histological methods for measurement of liver fibrosis, scores based on serum markers have been demonstrated good tools for the prediction of severity of liver fibrosis [37] and are widely used both in the general population and in HIV-infected patients [21, 36, 38-40].

\section{Conclusions}

In conclusion, in a cohort of HIV-infected males complaining of sexual dysfunction, detailed endocrinologic evaluation detected hypogonadism in about one third of patients. Hypogonadism might be related to different pathophysiologic mechanisms, among which for the first time we found that liver fibrosis causing increase of SHBG was the primum movens of compensated forms of hypogonadism.

Acknowledgements SP received a fellowship from Associazione Davide Rodella Onlus.

Funding Open Access funding provided by Università degli Studi di Brescia. No specific funding was used for this manuscript.

Availability of data and material Data are available upon motivate requests.

\section{Compliance with ethical standards}

Conflict of interest On behalf of all authors, the corresponding author states that there is no conflict of interest.

Ethics approval Ethic Committee of Brescia Province (Comitato Etico di Brescia-August 2020 NP 3898).

Consent to participate and for publication As this study had a retrospective design and was based on routinely collected data, patients' informed consent was not required.

Open Access This article is licensed under a Creative Commons Attribution 4.0 International License, which permits use, sharing, adaptation, distribution and reproduction in any medium or format, as long as you give appropriate credit to the original author(s) and the source, provide a link to the Creative Commons licence, and indicate if changes were made. The images or other third party material in this article are included in the article's Creative Commons licence, unless indicated otherwise in a credit line to the material. If material is not included in the article's Creative Commons licence and your intended use is not permitted by statutory regulation or exceeds the permitted use, you will need to obtain permission directly from the copyright holder. To view a copy of this licence, visit http://creativecommons.org/licenses/by/4.0/.

\section{References}

1. Richard-Eaglin A (2018) Male and female hypogonadism. Nurs Clin N Am 53(3):395-405. https://doi.org/10.1016/j. cnur.2018.04.006

2. Ross A, Bhasin S (2016) Hypogonadism: its prevalence and diagnosis. Urol Clin N Am 43(2):163-176. https://doi.org/10.1016/j. ucl.2016.01.002

3. Morales A, Bebb RA, Manjoo P, Assimakopoulos P, Axler J, Collier C, Elliott S, Goldenberg L, Gottesman I, Grober ED, Guyatt 
GH, Holmes DT, Lee JC, Deficiency CMsHFMGTFoT (2015) Diagnosis and management of testosterone deficiency syndrome in men: clinical practice guideline. CMAJ 187(18):1369-1377. https://doi.org/10.1503/cmaj.150033

4. Rochira V, Guaraldi G (2014) Hypogonadism in the HIV-infected man. Endocrinol Metab Clin N Am 43(3):709-730. https://doi. org/10.1016/j.ecl.2014.06.005

5. Lefrère JJ, Laplanche JL, Vittecoq D, Villette JM, Fiet J, Modai J, Dreux C (1988) Hypogonadism in AIDS. AIDS 2(2):135-136

6. Gomes AR, Souteiro P, Silva CG, Sousa-Pinto B, Almeida F, Sarmento A, Carvalho D, Freitas P (2016) Prevalence of testosterone deficiency in HIV-infected men under antiretroviral therapy. BMC Infect Dis 16(1):628. https://doi.org/10.1186/s12879-016-1892-5

7. Pongener N, Salam R, Ningshen R, Visi V, Wairokpam T, Devi LS (2019) A study on hypogonadism in male HIV patients in northeastern part of India. Indian J Sex Transm Dis AIDS 40(1):20-24. https://doi.org/10.4103/ijstd.IJSTD_67_17

8. Eendebak RJAH, Ahern T, Swiecicka A, Pye SR, O'Neill TW, Bartfai G, Casanueva FF, Maggi M, Forti G, Giwercman A, Han TS, Słowikowska-Hilczer J, Lean MEJ, Punab M, Pendleton N, Keevil BG, Vanderschueren D, Rutter MK, Tampubolon G, Goodacre R, Huhtaniemi IT, Wu FCW, Group E (2018) Elevated luteinizing hormone despite normal testosterone levels in older men-natural history, risk factors and clinical features. Clin Endocrinol (Oxf) 88(3):479-490. https://doi.org/10.1111/ cen. 13524

9. Corona G, Rastrelli G, Dicuio M, Concetti S, Minnetti M, Pivonello R, Isidori AM, Sforza A, Maggi M (2020) Subclinical male hypogonadism. Miner Endocrinol. https://doi.org/10.23736/S0391 -1977.20.03208-3

10. Tajar A, Forti G, O’Neill TW, Lee DM, Silman AJ, Finn JD, Bartfai G, Boonen S, Casanueva FF, Giwercman A, Han TS, Kula K, Labrie F, Lean ME, Pendleton N, Punab M, Vanderschueren D, Huhtaniemi IT, Wu FC, Group E (2010) Characteristics of secondary, primary, and compensated hypogonadism in aging men: evidence from the European Male Ageing Study. J Clin Endocrinol Metab 95(4):1810-1818. https://doi.org/10.1210/ jc.2009-1796

11. Monroe AK, Dobs AS, Palella FJ, Kingsley LA, Witt MD, Brown TT (2014) Morning free and total testosterone in HIV-infected men: implications for the assessment of hypogonadism. AIDS Res Ther 11(1):6. https://doi.org/10.1186/1742-6405-11-6

12. Sinclair M, Grossmann M, Gow PJ, Angus PW (2015) Testosterone in men with advanced liver disease: abnormalities and implications. J Gastroenterol Hepatol 30(2):244-251. https://doi. org/10.1111/jgh.12695

13. Charni-Natan M, Aloni-Grinstein R, Osher E, Rotter V (2019) Liver and steroid hormones-can a touch of p53 make a difference? Front Endocrinol (Lausanne) 10:374. https://doi.org/10.3389/ fendo.2019.00374

14. Himoto T, Fujita K, Sakamoto T, Nomura T, Morishita A, Yoneyama H, Haba R, Masaki T (2018) Clinical efficacy of free androgen index, a surrogate hallmark of circulating free testosterone level, in male patients with HCV-related chronic liver disease. J Clin Biochem Nutr 63(3):238-245. https://doi.org/10.3164/ jcbn.18-30

15. Hua X, Sun Y, Zhong Y, Feng W, Huang H, Wang W, Zhang T, Hu $\mathrm{Y}$ (2014) Low serum sex hormone-binding globulin is associated with nonalcoholic fatty liver disease in type 2 diabetic patients. Clin Endocrinol (Oxf) 80(6):877-883. https://doi.org/10.1111/ cen. 12360

16. Kim S, Kwon H, Park JH, Cho B, Kim D, Oh SW, Lee CM, Choi $\mathrm{HC}$ (2012) A low level of serum total testosterone is independently associated with nonalcoholic fatty liver disease. BMC Gastroenterol 12:69. https://doi.org/10.1186/1471-230X-12-69
17. Tian GX, Sun Y, Pang CJ, Tan AH, Gao Y, Zhang HY, Yang XB, Li ZX, Mo ZN (2012) Oestradiol is a protective factor for nonalcoholic fatty liver disease in healthy men. Obes Rev 13(4):381387. https://doi.org/10.1111/j.1467-789X.2011.00978.x

18. Lazo M, Zeb I, Nasir K, Tracy RP, Budoff MJ, Ouyang P, Vaidya D (2015) Association between endogenous sex hormones and liver fat in a multiethnic study of atherosclerosis. Clin Gastroenterol Hepatol 13(9):1686-1693.e1682. https://doi.org/10.1016/j. cgh.2014.12.033

19. Gawrieh S (2015) Sex hormones, sex hormone-binding globulin, and liver fat: which came first, the chicken or the egg? Clin Gastroenterol Hepatol 13(9):1694-1696. https://doi.org/10.1016/j. cgh.2015.04.182

20. Sarkar M, Yates K, Suzuki A, Lavine J, Gill R, Ziegler T, Terrault N, Dhindsa S (2019) Low testosterone is associated with nonalcoholic steatohepatitis (NASH) and severity of NASH fibrosis in men with NAFLD. Clin Gastroenterol Hepatol. https://doi. org/10.1016/j.cgh.2019.11.053

21. Fujihara Y, Hamanoue N, Yano H, Tanabe M, Akehi Y, Nomiyama T, Yanase T (2019) High sex hormone-binding globulin concentration is a risk factor for high fibrosis- 4 index in middle-aged Japanese men. Endocr J 66(7):637-645. https://doi.org/10.1507/ endocrj.EJ18-0505

22. Corona G, Goulis DG, Huhtaniemi I, Zitzmann M, Toppari J, Forti G, Vanderschueren D, Wu FC (2020) European Academy of Andrology (EAA) guidelines on investigation, treatment and monitoring of functional hypogonadism in males: endorsing organization: European Society of Endocrinology. Andrology. https://doi.org/10.1111/andr.12770

23. Lin ZH, Xin YN, Dong QJ, Wang Q, Jiang XJ, Zhan SH, Sun Y, Xuan SY (2011) Performance of the aspartate aminotransferaseto-platelet ratio index for the staging of hepatitis C-related fibrosis: an updated meta-analysis. Hepatology 53(3):726-736. https ://doi.org/10.1002/hep. 24105

24. Sterling RK, Lissen E, Clumeck N, Sola R, Correa MC, Montaner J, Sulkowski SM, Torriani FJ, Dieterich DT, Thomas DL, Messinger D, Nelson M, Investigators AC (2006) Development of a simple noninvasive index to predict significant fibrosis in patients with HIV/HCV coinfection. Hepatology 43(6):13171325. https://doi.org/10.1002/hep. 21178

25. Corona G, Maseroli E, Rastrelli G, Sforza A, Forti G, Mannucci E, Maggi M (2014) Characteristics of compensated hypogonadism in patients with sexual dysfunction. J Sex Med 11(7):1823-1834. https://doi.org/10.1111/jsm.12549

26. Lamm S, Chidakel A, Bansal R (2016) Obesity and hypogonadism. Urol Clin N Am 43(2):239-245. https://doi. org/10.1016/j.ucl.2016.01.005

27. De Vincentis S, Decaroli MC, Fanelli F, Diazzi C, Mezzullo M, Morini F, Bertani D, Milic J, Carli F, Cuomo G, Santi D, Tartaro G, Tagliavini S, De Santis MC, Roli L, Trenti T, Pagotto U, Guaraldi G, Rochira V (2021) Health status is related to testosterone, estrone and body fat: moving to functional hypogonadism in adult men with HIV. Eur J Endocrinol 184(1):107-122. https ://doi.org/10.1530/EJE-20-0855

28. Maffezzoni F, Porcelli T, Delbarba A, Pezzaioli LC, Properzi M, Cappelli C, Castelli F, Quiros-Roldan ME, Ferlin A (2020) Hypogonadism and bone health in men with HIV. Lancet HIV 7(11):e782-e790. https://doi.org/10.1016/S2352-3018(20)30236 $-8$

29. Rochira V, Diazzi C, Santi D, Brigante G, Ansaloni A, Decaroli MC, De Vincentis S, Stentarelli C, Zona S, Guaraldi G (2015) Low testosterone is associated with poor health status in men with human immunodeficiency virus infection: a retrospective study. Andrology 3(2):298-308. https://doi.org/10.1111/andr.310

30. Crum-Cianflone NF, Bavaro M, Hale B, Amling C, Truett A, Brandt C, Pope B, Furtek K, Medina S, Wallace MR (2007) 
Erectile dysfunction and hypogonadism among men with HIV. AIDS Patient Care STDS 21(1):9-19. https://doi.org/10.1089/ apc.2006.0071

31. Roubenoff R, Grinspoon S, Skolnik PR, Tchetgen E, Abad L, Spiegelman D, Knox T, Gorbach S (2002) Role of cytokines and testosterone in regulating lean body mass and resting energy expenditure in HIV-infected men. Am J Physiol Endocrinol Metab 283(1):E138-145. https://doi.org/10.1152/ajpendo.00426.2001

32. Karagiannis A, Harsoulis F (2005) Gonadal dysfunction in systemic diseases. Eur J Endocrinol 152(4):501-513. https://doi. org/10.1530/eje.1.01886

33. Santi D, Brigante G, Zona S, Guaraldi G, Rochira V (2014) Male sexual dysfunction and HIV - a clinical perspective. Nat Rev Urol 11(2):99-109. https://doi.org/10.1038/nrurol.2013.314

34. Rochira V, Zirilli L, Orlando G, Santi D, Brigante G, Diazzi C, Carli F, Carani C, Guaraldi G (2011) Premature decline of serum total testosterone in HIV-infected men in the HAART-era. PLoS ONE 6(12):e28512. https://doi.org/10.1371/journal.pone.00285 12

35. Moreno-Pérez O, Escoín C, Serna-Candel C, Portilla J, Boix V, Alfayate R, González-Sánchez V, Mauri M, Sánchez-Payá J, Picó A (2010) The determination of total testosterone and free testosterone (RIA) are not applicable to the evaluation of gonadal function in HIV-infected males. J Sex Med 7(8):2873-2883. https ://doi.org/10.1111/j.1743-6109.2010.01886.x

36. Polyzos SA, Mantzoros CS (2014) Necessity for timely noninvasive diagnosis of nonalcoholic fatty liver disease. Metabolism 63(2):161-167. https://doi.org/10.1016/j.metabol.2013.10.010

37. Lee J, Vali Y, Boursier J, Spijker R, Anstee QM, Bossuyt PM, Zafarmand H (2020) Prognostic accuracy of FIB-4, NAFLD fibrosis score, and APRI for NAFLD-related events: a systematic review. Liver Int. https://doi.org/10.1111/liv.14669
38. Miyauchi S, Miyake T, Miyazaki M, Eguchi T, Niiya T, Yamamoto S, Senba H, Furukawa S, Matsuura B, Hiasa Y (2017) Free testosterone concentration is inversely associated with markers of liver fibrosis in men with type 2 diabetes mellitus. Endocr J 64(12):1137-1142. https://doi.org/10.1507/endocrj.EJ17-0225

39. Lemoine M, Assoumou L, De Wit S, Girard PM, Valantin MA, Katlama C, Necsoi C, Campa P, Huefner AD, Schulze Zur Wiesch J, Rougier H, Bastard JP, Stocker H, Mauss S, Serfaty L, Ratziu V, Menu Y, Schlue J, Behrens G, Bedossa P, Capeau J, Ingiliz P, Costagliola D, Group A-E (2019) Diagnostic accuracy of noninvasive markers of steatosis, NASH, and liver fibrosis in HIVmonoinfected individuals at risk of nonalcoholic fatty liver disease (NAFLD): results from the ECHAM Study. J Acquir Immune Defic Syndr 80(4):e86-e94. https://doi.org/10.1097/QAI.00000 00000001936

40. Chalouni M, Sogni P, Miailhes P, Lacombe K, Poizot-Martin I, Chas J, Vittecoq D, Neau D, Aumaitre H, Alric L, Piroth L, Bouchaud O, Katlama C, Morlat P, Lascoux-Combe C, Gervais A, Naqvi A, Rosenthal E, Garipuy D, Barange K, Esterle L, Salmon D, Wittkop L, Group ACHs (2019) Liver stiffness and fibrosis-4 alone better predict liver events compared with aspartate aminotransferase to platelet ratio index in a cohort of human immunodeficiency virus and hepatitis $C$ virus co-infected patients from ANRS CO13 HEPAVIH cohort. Eur J Gastroenterol Hepatol 31(11):1387-1396. https://doi.org/10.1097/MEG.0000000000 001408

Publisher's Note Springer Nature remains neutral with regard to jurisdictional claims in published maps and institutional affiliations. 